\title{
LABOR DE ANDRÉS MANUEL DEL RIO EN MÉXICO: PROFESOR EN EL REAL SEMINARIO DE MINERÍA E INNOVADOR TECNOLÓGICO EN MINAS Y FERRERÍAS ${ }^{1}$
}

\author{
José Alfredo Uribe Salas \\ Facultad de Historia, UMSNH. Instituto de Historia, CSIC
}

\begin{abstract}
RESUMEN
El trabajo analiza la formación científica y tecnológica de Andrés del Río en Europa, y su desempeño profesional en Nueva España a fines del siglo XVIII y principios del XIX. Se estudia su práctica científica en el Real Seminario de Minería de la ciudad de México como una forma de cultura, y por lo tanto se examina la «práctica científica» de Andrés del Río y sus objetivos desde una perspectiva historicista y cultural. Del Río contribuyó a forjar una cultura científica como parte del imaginario colectivo del nuevo país de residencia. Pero serían los encargos de desaguar las minas de Morán en el distrito minero de Real del Monte y el establecimiento de una ferrería en la sierra de Coalcomán, en el antiguo Obispado de Michoacán, las que dejaron ver sus dotes de tecnólogo y la pericia en el diseño, proyección y ejecución de dos obras de ingeniería, una hidráulica y la otra industrial, las primeras de su género en el nuevo continente.
\end{abstract}

PALABRAS CLAVE: Andrés Manuel del Río, formación científica, Real Seminario de Minería, ferrería de Guadalupe, Nueva España, siglos XVIII y XIX.

\begin{abstract}
This article analyzes the scientific and technological training of Andrés del Río in Europe and, his professional activities in New Spain at the end of the eighteenth and the beginning of the nine-

1 Este trabajo forma parte de una investigación mayor sobre el tema, que se realiza en el Consejo Superior de Investigaciones Científicas, Madrid, España, vinculado al proyecto de investigación del Dr. Miguel Ángel Puig-Samper con No de Ref. BHA 2003-04414-C03-01, financiado por la Dirección General de Investigación, Ministerio de Educación y Ciencia, y en el marco del Programa: Estancias de profesores e investigadores extranjeros, de acreditada experiencia, en régimen de año sabático en España. No de referencia: SAB2004-0020. Secretaría de Estado de Universidades e Investigación, Ministerio de Educación y Ciencia.
\end{abstract}


teenth century. I study his scientific practice at Mexico City's Royal Mining Seminary as a form of culture; therefore, this research examines the «scientific practice» and goals of Andrés del Río from a historicist and cultural perspective. Del Río contributed to forge a scientific culture that became part of the collective imaginary in his new country of residence. However his direction in the draining of the Morán mines in the mining district of Real del Monte and the establishment of the ferreria (pre-industrial iron smelter) of Guadalupe in the Coalcomán highlands, in the former Michoacán Bishopric, allowed him to show his abilities as a technician and his skill in the design, projection and execution of two engineering projects (one hydraulic, the other industrial) - the first of their genre in the New World.

KEY WORDS: Andrés Manuel del Río, scientific training, Royal Mining Seminary, ferrería de Guadalupe, New Spain-eighteenth and nineteenth century.

\section{INTRODUCCIÓN}

Entre finales del siglo XVIII y principio del XIX asistimos a una transformación de la concepción del mundo. De la ponderación de la voluntad divina que soporta un orden eterno y universal, se transita en la búsqueda de manifestaciones complejas que dejan ver la actividad de la naturaleza y el universo como autónomas con relación a un ser superior que todo lo ordena y lo define.

En la búsqueda del origen de la vida surgen las más espectaculares teorías sobre la evolución de los reinos vegetal, animal y mineral. Los hombres que las cultivan se asocian y surgen las primeras sociedades de historia natural, en la que se agrupan los hombres dedicados al estudio de las manifestaciones en los tres reinos, plenamente aceptados; las exploraciones se multiplican a los confines del planeta y los gobiernos dictan políticas tendientes a financiar las nuevas investigaciones mediante la creación de instituciones especializadas tanto en su enseñanza como en la producción de nuevos conocimientos «útiles».

La segunda mitad del siglo XVIII vivió una intensa transformación en sus estructuras económicas, políticas y culturales. En el ámbito científico, algunos gobiernos europeos impulsaron verdaderas reformas en sus sistemas de enseñanza, crearon instituciones para el cultivo de las ciencias, financiaron expediciones a diversos puntos geográficos del planeta y contrataron los servicios de reconocidos hombres de ciencia. Estos, con el tiempo, crearon sus propias asociaciones y revistas para comunicar sus hallazgos, compartir sus preocupaciones y negociar con los gobiernos en turno políticas públicas en beneficio del saber científico.

En Alemania, Francia, Gran Bretaña, Suecia y España se establecieron Gabinete de Historia Natural, Academias, Jardines botánicos, Escuelas para la enseñanza de los saberes reunidos y programas para la recolección, clasifica- 
ción y estudio de las especies de los reinos vegetal, animal y mineral, como parte de un valor estratégico del conocimiento científico para expandirse sobre los cuatro puntos cardinales del planeta y aprovechar «racionalmente» sus recursos naturales.

En las décadas finales del siglo XVIII, la minería de la plata en el Nuevo mundo languidecía lejos del antiguo esplendor, como consecuencia del agotamiento de los filones argentíferos. Precisamente en esta etapa de declive de la mina de Potosí, la preocupación del gobierno de España por las cuestiones mineras se demostró incorporando primero en Almadén los avances técnicos más recientes desarrollados en Europa, para después traspasarlos a las explotaciones americanas. Es a partir de esta época cuando se desarrolla el mayor apoyo y colaboración científicos entre España e Hispanoamérica. Así, en 1777, el Ministro José Gálvez nombra Director de las Minas de Almadén al eminente minero alemán Enrique Cristóbal Storr, con la obligación de enseñar a los jóvenes las teorías modernas sobre Geometría Subterránea y Mineralogía.

Mediante este encargo se constituye la Academia de Minas de Almadén, anexa a la propia mina. Un cierto número de alumnos de sus primeras promociones, exhaustivamente preparados en Geometría Subterránea, Mineralogía y Laboreo de Minas, fueron enviados a América, aportando allí sus ideas y conocimientos tanto para la tecnificación de las explotaciones como para el avance de las ciencias en general. Algunos de ellos tendrían una actuación muy destacada en la minería del Nuevo Mundo, como Pedro Subiela, geómetra en la mina de Huancavélica, o Andrés del Río, profesor de Mineralogía en el Real Seminario de la Minería de México y descubridor del vanadio.

En este contexto fue el rey Carlos III quien trazó un vasto plan para llevar técnicos y expertos formados en la Escuela de Minas de Freigbert para que promovieran la minería en la Nueva España, exploraran su riqueza ${ }^{2}$ y generar conocimientos «útiles», y por Real Cédula de 1 de julio de 1776 se ordenó la erección en México de un Real Tribunal General de la Minería, autorizado

2 Puig y Larraz, G. (1898), «Viajes de estudio por Europa (Francia, Austria, Alemania Central, Prusia, Holanda, Suecia, Noruega e Inglaterra) durante los años 1788 a 1795. Cartas científico-familiares de D. Nabuel de Angulo y Correa recogidas, coleccionadas y anotadas por...», Boletín de la Sociedad Geográfica de Madrid, tomo XL, 1898, pp. 145-192, y 260295; tomo XLI, 1899, pp. 23-55, 193-223 y 283-301; tomo XLII, 1900, pp. 37-56, 60-82 у 127-162.; Pelayo, F, y Garilleti, R. (1992), «La formación y actividades botánicas de A. J. Cavanilles», Asclepio. Revista de Historia de la Medicina y de la Ciencia, Vol. XLIV, pp. 129-154, y GARCíA BELMER, A, y BERTOMÉu SÁNCHEZ, J. R. (2001), «Viajes a Francia para el estudio de la química, 1770-1833», Asclepio. Revista de Historia de la Medicina y de la Ciencia, Vol. LIII, pp. 95-139. 
para crear un banco de avíos cuyos fondos deberían ser aplicados al fomento de las minas y el sostenimiento de un Colegio Metálico ${ }^{3}$.

La creación del Real Seminario de Minería, que fue inaugurado el $1^{\circ}$ de enero de 1792, obedeció tanto al espíritu ilustrado de Carlos III como a los apremios del gremio de mineros novohispanos por resolver la grave crisis en que se encontraba el principal ramo de riqueza ${ }^{4}$. La nueva institución que articularía a lo largo del siglo XIX los esfuerzos y las prácticas científicas de una comunidad académica en ascenso, fue el resultado de intensas negociaciones entre el monarca español y el gremio de mineros, ambos interesados en los adelantos técnico-científicos de la actividad y en el incremento de la derrama económica de suyo propia. A estos intereses concretos, ubicados fuera de la ciencia, habría que sumar, a partir de los años de 1792-1795, la conformación de un proyecto «científico» en manos de sus profesores ${ }^{5}$, encaminado a sociabilizar las controversias teóricas entre neptunistas y plutonistas ${ }^{6}$; es-

3 Sellés, M., Peset, J. L., y Lafuente, A. (Compiladores), Carlos III y la ciencia de la Ilustración, Madrid, Alianza Universitaria, 1988. SALDAÑA, J. J. (1996), «Ciencia y felicidad pública en la Ilustración americana», SALDAÑA, J. J. (Coordinador), Historia social de las ciencias en América Latina, México, Grupo Editorial Miguel Ángel Porrúa, Universidad Nacional Autónoma de México, pp. 151-202.

4 Ramírez, S. (1890), Datos para la Historia del Colegio de Minería, México, Imprenta del Gobierno Federal en el ExArzobispado, pp. 20-61. GALvez CAÑERo Y AlzolA, A. (1933), "Apuntes biográficos de Fausto de Elhuyar y de Zubice», Boletín del Instituto Geológico y Minero, tomo LIII, núm. 8, pp. 379-629; PESET, J. L. (1987), Ciencia y Libertad. El papel del cientifico ante la independencia americana, Madrid, CSIC, pp. 143-267; CASTILLO Martos, M. (2005), Creadores de la ciencia moderna en España y América. Ulloa, los Delhuyar y del Río descubre el platino, el wolframio y el vanadio, España, Muñoz Moya Editores Extremeños, pp. 197-241; Pelayo, F. y ReBoK, S. (2002-2003), «Fausto de Elhuyar y la Societat der Bergbaukunde. Un proyecto científico de red europea para la difusión de las prácticas minero-metalúrgicas», Cronos, Vol. 5-6, pp. 67-90. URIBE SALAS, J. A, y CORTÉS Zavala, M. T. (2006), «Andrés del Río, Antonio del Castillo y José G. Aguilera en el desarrollo de la ciencia mexicana del siglo XIX», Revista de Indias (enviado para su evaluación). Una visión general del proceso de institucionalización de las ciencias en México del siglo XIX puede consultarse en Azuela, L. F. Guevara Fefer, R. (1998), «La ciencia en México en el siglo XIX: una aproximación historiográfica». Asclepio. 50 (2), pp. 77-105.

5 Archivo Histórico del Palacio de Minería (AHPM), Plan del Colegio de Minería, presentado al Real Tribunal general por su director, ML 90 B/1789-1800/fs. 5-14. Manuscrito.

6 En las etapas de formación de la geología numerosas personas tuvieron diferentes visiones sobre la naturaleza de su contenido y los métodos de estudio. Hubo, por ejemplo, una gran controversia entre neptunistas y vulcanistas (neptunistas vs plutonistas, 1790-1810). Más importante fue, sin embargo, el debate entre uniformistas y catastrofistas, porque el resultado del mismo, tuvo un importante efecto sobre la subsiguiente aceptación de la hipótesis de la deriva continental. 
tandarizar determinadas prácticas cognoscitivas de validación de resultados; creación de asociaciones científicas y publicaciones periódicas donde dar a conocer los hallazgos y debatir los problemas disciplinares.

Andrés del Río fue uno de los hombres de ciencia más conspicuos que llegaron a Nueva España, contratados por el gobierno español para que se hiciera cargo de la llamada «Cáthedra quarta del Colegio Metálico de México», o sea la cátedra de Mineralogía» ${ }^{7}$. Por su desempeño profesional a lo largo de su vida, primero en Nueva España y después en el México independiente, bien puede considerársele en la acepción moderna de «científico», como profesional de la ciencia. Miembro de una comunidad «científica» organizada, y «activo» de la reivindicación de la ciencia en la sociedad, pugnó siempre por la organización de la ciencia en torno a las financiaciones públicas de los gobiernos, subrayando el aspecto práctico frente al teórico.

Hombres de ciencia de la talla de Andrés del Río, se dedicaron a definir con mejor precisión sus instrumentos de búsqueda, el acopio de información y los procesos cognoscitivos de comprensión e interpretación de sí misma; de sus relaciones con la realidad circundante y de sus capacidades, siempre crecientes, para recrear sus propios conocimientos y reinventar y/o innovar modelos, teorías, procedimientos y técnicas, tal y como lo hiciera el propio Del Río cuando se le encomendó desaguar las minas de Moran y establecer la primera ferrería en la América española. Pero también pusieron empeño en desentrañar los elementos de la naturaleza, su composición orgánica, sus sistemas de relaciones complejas, incluso más allá de su carácter utilitario o socialmente útil, colocándose obligatoriamente en el centro del debate sobre el origen del planeta, de las especies y de la vida misma, y desde luego a la confrontación de sus resultados de investigación con los paradigmas en boga.

En el presente trabajo se hace particular hincapié en la formación científica y tecnológica de Andrés del Río en Europa, y su desempeño profesional en Nueva España a fines del siglo XVIII y principios del XIX. Se estudia su práctica científica en el Real Seminario de Minería de la ciudad de México

7 Rubinovich Kogan, R. (1992), «Andrés Manuel del Río y sus Elementos de Orictognosia de 1795-1805», introducción a la edición facsimilar de Andrés Manuel del Río, 1795-1805, Elementos de Orictognosia, México, UNAM, 1992, pp. 3-70; CORDERo BORBOA, A. E. Referencias Recientes para la Historia de la Cristalografia Mexicana, Instituto de Física, Universidad Nacional Autónoma de México. http://www1.unam.mx/smcr/Noticias/referencias.htm. ARNÁIZ Y FrEG, A. (1966), «D. Andrés Manuel del Río y su ilustre magisterio en México», PRIETO, C, SANDOval Vallarta, M, Bargalló, M, ArnáIz y Freg, A. Andrés Manuel del Río y su obra científica, México, Compañía Fundidora de Fierro y Acero de Monterrey, p. 30. 
como una forma de cultura, y por lo tanto se examina la «práctica científica» de Andrés del Río y sus objetivos desde una perspectiva historicista y cultural. Del Río contribuyó a forjar una cultura científica como parte del imaginario colectivo del nuevo país de residencia. Pero serían los encargos de desaguar las minas de Morán en el distrito minero de Real del Monte y el establecimiento de una ferrería en la sierra de Coalcomán, en el antiguo Obispado de Michoacán, las que dejaron ver sus dotes de tecnólogo y la pericia en el diseño, proyección y ejecución de dos obras de ingeniería, una hidráulica y la otra industrial, las primeras de su género en el nuevo continente.

\section{FORMACIÓN ACADÉMICA Y CIENTÍFICA DE ANDRÉS MANUEL DEL RÍO}

La vida de Andrés Manuel del Río Fernández estuvo marcada por los renovados vientos que trajo la revolución científico industrial, a cuyo proceso se sumó y de la que fue parte integrante ${ }^{8}$. Este hombre de ciencia nació un 10 de noviembre de 1764 en la ciudad de Madrid, España, y murió a los 85 años, el 23 de marzo de 1849 en la ciudad de México.

Sus padres, de origen modesto, le enseñaron las primeras letras y cultivaron en él una actitud de gozo e incertidumbre frente a los misterios que encerraba la vida, la naturaleza y el universo. A la edad de 9 años sus progenitores lo matricularon en el Real Colegio de San Isidro, en Madrid. En 1780, a los 16 años se graduó de bachiller bajo la tutela de su profesor José Solano. En cursos universitarios «superiores», destacó entre sus condiscípulos, con excelente aprovechamiento en Física Experimental, lo que le valió el reconocimiento de «Concursante más aprovechado»".

Su esmero y dedicación al estudio no pasó desapercibido para sus mentores, quienes lo promovieron en las instancias superiores de gobierno para obtener una pensión de estudio. Esta llegó el 15 de junio de 1782, avalada por José María de Gálvez, Ministro de Indias, para estudiar en la Real Academia

8 Prieto, C., Sandoval Vallarta, M., Bargalló, M. y Arnáiz Y Freg, A. (1966), Andrés Manuel del Río y su obra científica. Segundo centenario de su natalicio (1764-1849), México, Cia. Fundidora de Fierro y Acero de Monterrey, pp. 11-79; RuBINOVICH, R. (1992), pp. 3-70; AMORÓs PORTOLÉS, J. L. (1985), «Andrés del Río y su obra», introducción a la edición facsimilar de Andrés Manuel del Río, 1795-180, Elementos de Orictognosia, Madrid, Universidad Complutense, pp. 13-62; CASTILlO MARTOS, M. (2005), pp. 197-241.

9 (1978) «Andrés Manuel del Río», Enciclopedia de México, México, Enciclopedia de México, tomo XI, p. 133. 
de Minas de Almadén fundada en 1777, diez años después que la primera Academia de Minas de Freiberg, en Sajonia ${ }^{10}$. Un año entero pasó Del Río en la Escuela y Minas de Almadén ${ }^{11}$, dirigida en ese entonces por Heinrich Christophe Störr, mineralogista germano al servicio de la corona española ${ }^{12}$. Con Heinrich Christophe Störr, tanto Andrés del Río, como sus condiscípulos Andrés José Rodríguez, Pedro Subirla, y otras más, recibirían las enseñanzas sobre las formaciones mineralógicas y la explotación de las minas de manera completa y económicas ${ }^{13}$. Los dos primeros serían destinados tiempo después como expertos al Real Seminario de Minería de México, en tanto que el tercero prestaría sus servicios en las minas de Huancavelica14.

A partir de abril de 1785, Del Río iniciaría un peregrinar por las más prestigiosas instituciones europeas y entraría en contacto con los hombres de ciencia de más renombre, para terminar en el año de 1794 cumpliendo con un mandato oficial que lo llevaría a tierras americanas, en un largo viaje de tres meses ${ }^{15}$. Primero se trasladó a París para perfeccionar su adiestramiento en Química, Física, Matemáticas y Ciencias Naturales. En la ciudad de «las lu-

10 AnÓnimo (1878), Centenario de la Escuela de Minas de España (1777-1787), Escuela de Minas, Madrid; RumEu DE ARMAs, R., «La Real Escuela de Mineralogía de Madrid (17891808)» Hispania, núm. 39, p. 311.

11 Prieto, C. (1969), La minería en el Nuevo Mundo, Madrid, Revista de Occidente, p. 147.

12 Bargalló, M. (1965), «Andrés Manuel del Río. Descubridor del Vanadio», Ciencia Internacional, Vol. VI, núm. 1, p. 9. Störr escribió para la Escuela y Minas de Almadén un manual de mineralogía y geometría subterránea que facilitaba a los estudiantes la comprensión teórica de la geognosia; el conocimiento de los instrumentos de matemáticas, como la brújula, el nivel, el semicírculo, las escalas o la regla de metal; y el manejo de los instrumentos para el diseño tanto de los planos interiores como externos en las minas. LÓPEZ AZCONA, J. M. (1978), «La enseñanza de la minería en el mundo hispano durante el reinado de Carlos III (1759-1788)», Boletín Geológico y Minero, 1978, p. 77.

13 RamíRez, S. (1875), «Biografía del Sr. D. Andrés Manuel del Río. Primer Catedrático de Mineralogía del Colegio de México, escrito por el Ingeniero de Minas...» Boletín de la Sociedad de Geografia y Estadística de la República, (Tercera época), México, Imprenta de Díaz de León y White, tomo II, pp. 208-209.

14 Trabulse, E. (1983), Historia de la ciencia en México. Estudios y Textos, México, CONACYT, Fondo de Cultura Económica, pp. 50-51; RIERA, S. (1992), Tecnología de la ilustración, Madrid, Editorial Akal, pp. 13-16. FlORES CLAIR, E. (2000), Minería, educación y sociedad. El Colegio de Minería, 1774-1821, México, Col. Científica, núm. 419, Instituto Nacional de Antropología e Historia, pp. 21-107.

15 Uribe Salas, A. (2002), Historia de la Minería en Michoacán, México, Col. Historias y Procesos, núm. 2, Universidad Michoacana de San Nicolás de Hidalgo, Sociedad Mexicana de Mineralogía, Museo Tecnológico del Siglo XIX, Vol. 1, pp. 91-101. 
ces», Del Río con 21 años cumplidos se enfrasca de lleno en desentrañar los misterios de la tierra en la l'Ecole Royale des Mines, creada apenas dos años antes, en 1783; y en el Collège de France, fundado en 1774, con el profesor Jean D'Arcet (1725-1801) ${ }^{16}$, especialista en química y director de los trabajos de la porcelana de Sèvres, se inicia en el análisis de los minerales y porcelanas que aplicaría más tarde en una fábrica de porcelana en Puebla de los Ángeles, México ${ }^{17}$.

De París paso a la región de Sajonia de onda y larga tradición minerometalúrgica en centroeuropa, y se matricula en la Bergakademie de Freiberg ${ }^{18}$, para su adiestramiento «en el nuevo método de amalgamación de Born y a su vuelta lo aplicaran en las minas americanas» ${ }^{19}$. Ahí entró en contacto con el sabio profesor Abraham Gottlob Werner (1749-1817), uno de los padres de la mineralogía y la geología ${ }^{20}$. Asiste con sus condiscípulos a las lec-

16 Jean d'Arcet era un renombrado químico, y tenía fuerte inclinación por la geología y la medicina. Su obra Rapport sur la fabrication des savons, de 1795, constituye un verdadero tratado de química del siglo XVIII sobre la fabricación del jabón. La fabricación del jabón fue desarrollada por los árabes y refinada por europeo durante el renacimiento. Los jabones son hechos por la reacción de un álcali, tal como hidróxido del sodio, con los ácidos grasos. Los productos de esta reacción son las sales metálicas de ácidos grasos, conocidas comúnmente como jabón y glicerina. D'ARCET, J. (1795), Rapport sur la fabrication des savons, A Paris, De l'Imprimerie de R. Vater et Ass.

17 Del Río, M. Herrera, M. Del Moral, T. R. (1843), «Informe sobre la porcelana de Puebla», Siglo XIX, Año II, núm. 532, 10 de mayo, pp. 2-3, RAMíreZ, S. (1890), pp. 310-320; Robles, V. A. (1937), El Ilustre Maestro Andrés Manuel del Río, México, s/e, p. 11; BARGALLÓ, M. (1964), «Andrés Manuel del Río y el Bicentenario de su nacimiento (1764) (Su labor Geológica, Mineralógica y Minerometalúrgica)», Revista de la Sociedad Mexicana de Historia Natural, Vol. XXV, pp. 255-261.

18 Pelayo, F. y ReboK, S. (2004), «Un condiscípulo español de Alexander von Humboldt en la Bergakademie de Freiberg: Josef Ricarte y su informe sobre el método de amalgamación de Born (1788)», Asclepio. 56 (2), p. 91.: Pelayo, F, y Garilleti, R. (1992), «La formación y actividades botánicas de A. J. Cavanilles», Asclepio. Revista de Historia de la Medicina y de la Ciencia, Vol. XLIV, pp. 129-154, y GARCía BELMAR, A, y BERTOMÉu SÁNCHEZ, J. R. (2001), «Viajes a Francia para el estudio de la química, 1770-1833», Asclepio 53 LIII, pp. 95-139.

19 Pelayo, F. y ReboK, S. (2002-2003), «Fausto de Elhuyar y la Societat der Bergbaukunde. Un proyecto científico de red europea para la difusión de las prácticas minerometalurgicas», Cronos, Vol. 5-6, pp. 67-90.

20 Abraham Gottlib Werner (1749-1817), director de la Escuela de Minas de Friburgo (Sajonia), creada ex profeso para estudiar la naturaleza y estructura mineralizada del planeta, representa una figura clave en el estudio del origen del planeta tierra y en el desarrollo posterior de las ciencias de la Tierra, al proponer el primer sistema de clasificación e interpretación 
ciones de geometría subterránea y dibujo, a las de beneficio de minas, construcción de máquinas y metalurgia, mismos que cultivaría con esmero en su etapa americana. También cultiva la amistad de jóvenes aprendices: Josef Ricarte, Miguel Angulo, José Miaja, Juan López Peñalver y Enrique Schnellenbühe, que como él, habían dejado el sosiego y la certidumbre que proporciona la casa paterna y el ambiente familiar ${ }^{21}$.

Del Río aprendió de manos de su profesor Antón Ruprecht la naturaleza y las características de la geognosia, es decir, «la formación de las montañas, su estructura o cobertura interior, las vetas y venas que en ellas se encuentran, las sustancias de que se componen y los metales que cada género de ellas suelen encerrar dentro de sí», y desde luego, con «el arte de descubrir minas», trabajarlas, fortificarlas, abrir galerías y tiros para «entrar y salir de las minas, para sacar por medio de máquinas adecuadas los minerales, piedras y agua, para introducir las maderas que se necesitan, así para fortificar la mina, como para la construcción y compostura de las máquinas que obran dentro de ella» ${ }^{22}$.

Entre los condiscípulos de Andrés del Río, se encontraban también Dieudonné Sylvain Guy Tancrède de Gratet de Dolomieu (1750-1801), Alejandro de Humboltd (como alumno externo, a los cursos de la Bergakademie desde junio de 1791 hasta febrero de 1792) 23 $^{3}$, Horace Benedic Saussure (17401799), y Weaber. En la Bergakademie Del Río estudiaría orictognosia de la mano de su creador, y geometría subterránea con el profesor Lempi, a quien ayudaría a redactar un tratado sobre ésta materia, y que años después, «el Real Tribunal de Minería de México le encargó la traducción al castellano» ${ }^{24}$.

de rocas y paisajes, plenamente admitido en a finales del siglo XVIII y la primera mitad del XIX. El sistema propuesto por Werner se basa en una clasificación de ricas según un orden cronológico, siendo el elemento base de la clasificación la formación de estratos superpuestos unidos entre ellos con el fin de construir un sistema. Su método ponía énfasis en el estudio sistemático de lo que hoy conocemos como geología, sirviéndose, además, de todas las observaciones tomadas de la práctica cotidiana de la explotación minera. MofFAT, I. (1982), «Paradigmas en Geología: del Catastrofismo a la Tectónica de Placas», Geocrítica. Cuadernos críticos de Geografia Humana, Universidad de Barcelona, Año VII, núm. 42.

21 Pelayo y ReboK (2004), p. 94; Puig y Larraz, G. (1898), pp. 145-192, y 260-295; tomo XLI, 1899, pp. 23-55, 193-223 y 283-301; tomo XLII, 1900, pp. 37-56, 60-82 y 127-162.

22 Archivo General de Indias (AGI), Indiferente general, Leg. 1798, Exp. «De los mineros sajones que pasaron a las Indias. Incidencias 1786 a1793», fols. 540r-541v. Documento citado por PELAYO y ReBOK (2004), p. 92

23 VelázQuez de León, M. (1859), «Elogio Fúnebre del Barón de Humboldt», Anuario Estadístico del Colegio de Minería de México, edición facsímile, México, Universidad Autónoma de México, p. 72; Pelayo y ReBOK (2004), p. 95.

24 RAMíREZ (1875), pp. 251-253. 
Concluida su etapa formativa en Sajonia, pasó a Hungría y se inscribió en la Real Academia de Minas y Bosques de la ciudad de Schemnitz, en donde perfeccionó sus conocimientos en Química Analítica, Metalurgia y Aplicación de Geometría subterránea con el destacado profesor Antón von Rupprecht, a quien se le reconoce haber contribuido para que Franz Muller von Reiehenstein descubriera el telurio en 1784. También conoció Del Río las técnicas de amalgamación de minerales de plata por toneles de Born, y se familiarizó con el proceso que usaba hierro, introducido en Sajonia por Gellert, para separar el azufre de la plata en los minerales argentíferos que lo contenían. Fue condiscípulo una vez más de Alejandro de Humboltd y del geólogo berlinés Christian Leopold von Buch (1774-1853) — quien realizara entre 1815 y 1816 un interesante estudio sobre los volcanes canarios y sería el promotor responsable de lo que se considera el primer mapa geológico de Alemania (1826), y también de los primeros en Europa que determinaron que los granitos se formaron por procesos ígneos y que las montañas resultaron de una agitación en la corteza de tierra, alejándose de la teoría neptunista 25 - y del médico naturalista Luís Lindner, con quien compartiría, desde 1798, responsabilidades docentes y de investigación en el Real Seminario de Minería de México 26.

El 26 de noviembre de 1790 Del Río dio por concluida su estadía en Hungría. Una Real Orden lo destinaba, ahora, a las minas de cinabrio de Idra, fuente de abastecimiento de azogue de la corona española para las minas de sus posesiones en América. En una breve estancia en Idra, Andrés Manuel del Río se familiariza con los métodos y las técnicas de producción de tan preciada sustancia química, que era el sostén indiscutible del proceso de amalgamación y beneficio de plata, según el sistema inventado por el sevillano Bartolomé de Medina en el siglo XVI ${ }^{27}$. De Idra, Andrés del Río viaja a París en

25 Castillo Martos (2005), p. 200. Christian Leopold von Buch (1774-1853), geólogo y paleontólogo alemán, graduado en la Academia de Minas de Freiberg, Alemania; uno de los partidarios más influyentes y populares de la teoría neptunista (rocas de orígenes acuosos), elaborada y enseñada por el geólogo Abraham G. Werner, fundador de la influyente escuela Neptunista. Según esta teoría, en una época remota un océano cubrió toda la Tierra y toda la corteza terrestre se formó a partir de ese océano. No obstante, los últimos estudios realizados por von Buch encontraron defectos en la hipótesis de Werner. HeInRICH MAAR, J. (2004), «Aspectos históricos do ensino superior de química», Scientice zudia, Vol. 2, núm. 1, São Paulo, pp. 33-84,

26 HEINRICH MAAR (2004), pp. 39-76.

27 Véase el documentado estudio de BARgalló, M. (1969), La amalgamación de los minerales de plata en Hispanoamérica colonial, México, Compañía Fundidora de Fierro y Acero de Monterrey. 


\section{1 y visitó el Laboratorio del Arsenal dirigido por el prestigiado químico y hombre de ciencia Antoine Laurent Lavoisier ${ }^{28}$.}

28 PRIETO (1969), p. 147. En ese momento Lavoisier y el abate René Just Haüy (1743$1822)^{28}$ trabajaban en una obra enciclopédica que buscaba establecer «un nuevo sistema de pesos y medidas». Sus investigaciones habían avanzado lo suficiente pues ya en 1787 habían publicado Méthode de nomenclature chimique, que mostraba un conjunto sistemático de reglas para nombrar las substancias basado en las ideas químicas desarrolladas a finales del siglo XVIII, y que, entre otros aspectos, supusieron el abandono de la teoría del flogisto y la consolidación de nuevas ideas sobre la composición química ${ }^{28}$. ACEVES, P. (1990), Tratado elemental de Chimica por A. L. Lavoisier, (edición facsimilar y estudio preliminar de P. Aceves), México, UAM-X. Los cambios que ocurrieron en las explicaciones y en el lenguaje de la química, junto con el hecho de que fueran reconocidos como una revolución, tanto por los protagonistas como por autores posteriores, han llevado a historiadores de la ciencia como I. Bernard Cohen a afirmar que la «revolución química es un ejemplo paradigmático de una revolución en ciencia». De acuerdo con la interpretación más difundida, esta «revolución» consistió en el abandono de la teoría del flogisto y su reemplazamiento por una teoría sobre la combustión basada en la acción del oxígeno. En el marco de esta «revolución química» Méthode de nomenclature chimique tenía como fundamento el nuevo concepto de composición química que se consolidó a lo largo del siglo XVIII, que ha sido ya tratado en el apartado anterior. El punto de partida de la nueva nomenclatura lo constituyó la lista de substancias simples elaborada por Lavoisier a partir de la conocida definición que proponía «considerar como simples todas las substancias que no se habían podido descomponer». Eliminado el flogisto del campo de la química, los metales pasaron a formar parte de las substancias simples mientras que la mayor parte de las cales pasaron a ser substancias compuestas de un metal y oxígeno. No obstante, algunas substancias como la cal o la magnesia, aparecieron dentro de la famosa lista de treinta y tres substancias simples que figuran en el Traité élémentaire de chimie de Lavoisier, dado que no habían sido todavía analizadas. La lista también incluía algunos «radicales» como el «radical muriático», «radical fluórico» o «radical borácico» puesto que Lavoisier pensaba que los correspondientes ácidos no eran substancias simples sino formadas por estos radicales y oxígeno, a pesar de que había sido imposible descomponerlas.

La distinción entre substancias simples y compuestas permitió establecer nombres claramente diferentes para ambos tipos de substancias. En el Méthode de nomenclature chimique las substancias simples son nombradas con un nombre único, sin dar mucha importancia al criterio empleado para acuñar tal término. En la lista de elementos propuesta por Lavoisier encontramos términos formados según las propriedades químicas del elemento (oxígeno, hidrógeno), otros acuñados a partir del nombre del mineral de procedencia (tungsteno) e, incluso, nombres que procedían de la tradición alquímica (mercurio). Los autores del Méthode apenas prestaron atención a los nombres de los elementos, que, en general, continuaron siendo los que habían sido empleados hasta ese momento. Ver : Méthode de Nomenclature Chimique, proposée par MM. de Morveau, Lavoisier, Bertholet [sic], \& de Fourcroy. On y a joint Un nouveau Système de Caractères Chimiques, adaptés à cette Nomenclature, Paris, MM. Hassenfrazt \& Adet, 1787, 314 pp. 
Empero, las secuelas de la Revolución Francesa pudieron más que el prestigio y los frutos de la práctica científica. En agosto de 1793 fue cancelada toda actividad de la Academia de Ciencias de Francia, y Lavoisier fue arrestado y guillotinado el 8 de agosto de 1794. Ante una situación de tanta gravedad, a Del Río no le quedó otra salida que abandonar París y Francia, y establecerse en Escocia y en Cornwall ${ }^{29}$.

En Inglaterra, del Río retoma su perfeccionamiento en química y matemáticas, y se adiestra en el método de fundición de hierro y en el funcionamiento y manejo de la moderna maquinaria, producto de la Revolución Industrial inglesa. Esta experiencia resultaría decisiva cuando años después, respondiendo a otra encomienda de las autoridades de la Corona, establezca en 1805 la primera ferrería en la América española, muy cerca de las costas del mar Pacífico en el suroeste del afamado obispado y después intendencia de Michoacán, como veremos más adelante.

De Inglaterra, del Río paso a Viene, en donde poco tiempo después recibió de manos del embajador de España en Viene, marqués de Llano, un comunicado oficial en donde se le notificaba su traslado a la Nueva España, con carácter de catedrático en el recién establecido Real Seminario de Minería de la ciudad de México. A partir del día 28 de febrero de 1793, Andrés Manuel del Río contó con el nombramiento oficial de catedrático de mineralogía en el Real Seminario de Minería de Nueva España, aunque sólo entraría en funciones como profesor en abril de $1795^{30}$.

\section{ANDRÉs Manuel del Río y el Real Seminario de Minería de la CiUdad DE MÉXICO}

Andrés del Río dejó su país natal el 2 de agosto de 1794 al embarcarse en Cádiz, y después de una larga travesía llega al puerto de Veracruz el 20 de octubre del mismo año. A la ciudad de México arribó el 18 de diciembre trayendo consigo un valioso cargamento de libros, instrumentos, máquinas y reactivos químicos, con los cuales montó el primer gabinete de mineralogía en el Real Seminario de Minería ${ }^{31}$, que a partir de entonces, y hasta su muerte acaecida el 23 de marzo de 1849, sería su casa de la ciencia. No tuvo reposo

29 (1855), Diccionario Universal de Historia y Geografia, México, Imprenta de F. Escalante y Cía., p. 618; CASTILlo MARTOS (2005), p. 201.

30 Flores Clair (2000), pp. 60-69; CASTILlo Martos (2005), pp. 201-202.

31 RAMíREZ (1890), pp. 22-24. 
alguno, pues pasadas apenas las navidades elaboró una lista completa de «instrumentos, máquinas y aparatos» que debían comprarse en España, y recibe de manos del Director del Seminario, Fausto de Elhuyar, las primeras indicaciones y tareas que debería cumplir en adelante. El primer encargo que inauguraría su largo y fructífero desempeño científico en América fue, desde luego, la traducción del alemán del opúsculo de Werner, Nueva teoría sobre el origen de las vetas $(1791)^{32}$, para uso de los estudiantes, que debería estar lista para el inicio del primer curso de mineralogía que le fue programado el 27 de abril de 1895. Días después, el director Elhuyar participó al Real Tribunal, haber dispuesto que, de inmediato, el día 27, se hiciera la apertura de la clase de mineralogía, remitiéndole el oficio siguiente:

«Habiendo D. Andrés del Río, Catedrático de este Real Seminario puesto en el correspondiente orden las muestras de Piedras y Minerales que forman la colección que en el día posee este Establecimiento, y dispuesto así mismo la nomenclatura de los caracteres externos de los fósiles, necesaria para su exposición en los términos que reconocerá V. S. por las adjuntas tablas y su explicación en orden Alfabético, de que han sacado copia todos los Alumnos que deben seguir este años su clase, no hay ya embarazo para que desde luego se abra y de principio a ella el Lunes próximo 27 del que rige.

A este primer trabajo que comprende la parte preparatoria de la Orictognosio o conocimiento de los Fósiles, debe seguirse el formalizar ésta, exponiendo en ella su clasificación individual y las propiedades o caracteres propios de cada uno. En ello se ocupa en el día dicho D. Andrés, que tiene bastante adelantada la primera parte, que comprende la clase de las tierras, y estará concluida para cuando acabe la explicación de la preparatoria con que debe empezar, a fin de que los alumnos tengan siempre una obra para seguir y repasar sus lecciones.

Cuando esté concluida esta parte, daré cuanta a V. S. y expondré lo que juzgue conveniente se haga con ella.

Tanto por el tiempo que va ya corrido de este año, como por el que necesita dicho Catedrático para continuar la obra que esta trabajando, será necesario limite el presente año su enseñanza a sólo la Orictognosia; reservando dar principio a la del Laborio de las Minas, que por no haber aún los Modelos necesarios ni la obra correspondiente, sería aún de poco provecho empezarla por ahora.

Con el fin de que así este Catedrático como D. Francisco Bataller, que lo es de la Clase de Física, puedan también con más desahogo ir disponiendo la obra que para sus respectivas clases están trabajando, es conveniente que por ahora alternen por las mañanas en sus lecciones, dando cada uno tres por semana, para que así les queden las otras libres para todo trabajo, y se consiga por este medio lo concluyan cuanto antes, y que en lo sucesivo puedan sus Discípulos seguir sus lecciones sin los embarazos que en el día les ocasiona la falta de Obras Elementales adecuadas ${ }^{33}$.

32 RAMÍREZ (1890), pp. 125-126.

33 RAMÍREZ (1890), pp. 126-127. 
De lo escrito por Elhuyar se desprende una concepción moderna de la práctica científica encomendada a Andrés del Río y a sus correligionarios, que en adelante tendrían la responsabilidad de consolidar la institucionalización de las ciencias en el nuevo continente. Clementina Díaz y de Oviedo señala en su monumental obra Los veneros de la ciencia mexicana, que «tal parecen, en la intuición de Elhuyar, las tareas de un universitario de hoy día: la investigación y la docencia ${ }^{34}$.

Andrés del Río impartió su cátedra de mineralogía ininterrumpidamente de 1795 hasta 1805, y la de docimasia y ensayos entre 1798 y 1805, etapa que bien podría considerarse como de las más reposadas, tranquilas y productivas de su vida. En ese tiempo compaginó la docencia con sus trabajos de investigación, las traducciones de manuales y tratados sobre orictognosia, geognosia y geometría subterránea, y el indispensable ejercicio de exploración y trabajo de campo que lo llevaría a descubrir nuevos minerales y sustancias como el «Erythronium» ${ }^{35}$.

En abril de 1795 comenzó a dictar el primer curso de mineralogía (orictognosia) que llegó a darse en la Nueva España y publicó ese mismo año, la primera parte de Elementos de Orictognosia, donde describió a los minerales por sus caracteres exteriores y les asignó un lugar en la clasificación o sistema mineral de Werner, siguiendo la clasificación del mineralogista sueco Torbern Bergman (1735-1785) ${ }^{36}$. Su colega y amigo el mineralogista alemán Chritiano Hergen, colector del Real Gabinete de Historia Natural de Madrid, y traductor del alemán al español de La Orictognosia, escrita por Juan Federico Guillermo Widennann, escribió en una nota introductoria al libro intitulada «Aviso del Traductor», entre otras cosas lo siguiente:

«Estas y otras reflexiones semejantes me han determinado a traducir la Obra presente, tan moderna, tan clásica, y tan completa, que no necesito detenerme en elogios.

Tiene por base el sistema del célebre Profesor Werner, y se ocupa principalmente en los caracteres exteriores de los fósiles; pero no desprecia por esto la análisis química, antes bien se encuentra en esta Obra todas las que hay hechas en el día por los Químicos de mayor reputación.

34 Díaz y de Ovando, C. (1998), Los Veneros de la Ciencia Mexicana. Crónica del Real Seminario de Minería (1792-1892), México, Universidad Nacional Autónoma de México, Facultad de Ingeniería, México, tomo I, p. 60.

35 Bargalló, M. (1966), «Conveniencia de sustituir el nombre de Vanadium por el de Erythronium», Prieto, C., Sandoval Vallarta, M., Bargalló, M., Arnálz y Freg, A. pp. 77-79.

36 Rubinovich Kogan (1992), pp. 3-70; AMORÓs PortolÉs (1985), pp. 13-62. 
La Química debe mirarse siempre como el supremo tribunal, autorizado para rectificar nuestras clasificaciones...

Pero al mismo tiempo debemos confesar, que nos falta todavía la análisis química de muchos minerales, y que muchas de las que tenemos se contradicen, y se hallan lejos de aquella exactitud que necesariamente debían tener.

Repito que es preciso tener un idioma científico para hacerse entender de los estrangeros; pues si de un fósil nuevamente descubierto en España, remitimos a algún naturalista de otro país solo la análisis química, verá éste sin duda de qué partes constitutivas se compone la sustancia nueva; pero ¿cómo podrá formarse idea de su color, gravedad, cristalización? -en una palabra - de su figura? ni cómo podrá describirle a otro Naturalista?

Mi traducción estaba ya adelantada, cuando supe, que Don Andrés del Río, que había estudiado la Mineralogía baxo la dirección de Werner en Freiberg, destinado después por S. M. Católica para enseñar esa Ciencia en sus Américas, había conocido, como yo, que en este país faltaba un cuerpo sistemático de doctrina, para servir de base a la enseñanza de esta Ciencia. El primer tomo que publicó a este fin, pocos años ha, en América, me hizo ver, que animados ambos de un mismo zelo, seguíamos al mismo tiempo iguales principios mineralógicos; y esta concurrencia, lejos de desalentarme, me ha animado a trabajar con los mayores esfuerzos para realizarle» ${ }^{37}$.

Cuando Alejandro de Humboldt (1769-1859) visitó México en 1803 participó activamente en las labores del Real Seminario. Organizó excursiones a Chapultepec, la zona basáltica del pedregal del Xitle y al Peñon de los Baños, recogiendo datos y muestras de minerales y rocas que una vez en el Real Seminario de Minería sometió a ensayos químicos para su identificación. Andrés del Río que había coincidido en dos ocasiones con Humboldt en centroeuropa, en sus tiempos de estudiantes, aprovechó la estadía de su condiscípulo para mostrarle sus investigaciones, hallazgos y descubrimientos más recientes. El más importante y sonado fue el «eritronio» ${ }^{38}$, sobre el cual se han elaborado diversas teorías y explicaciones ${ }^{39}$.

37 WidennAnN, J. F. G. (1797), La Orictognosia, escrita por D. Juan Federico Guillermo Widennann, del Consejo de Minas del Duque de Würremberg, miembro de la Sociedad del beneficio de Minas, de la de los Amigos investigadores de la Naturaleza en Berlín, y de la económica de Leipsic, y Traducida por Don Christiano Bergen, colector del Real Gabinete de Historia Natural de Madrid, Madrid, en la Imprenta Real, 1797, pp. «Aviso del Traductor».

38 IZQuierdo, J. J. (1958), La primera casa de las ciencias en México. El Real Seminario de Minería (1792-1811), México, Ediciones Ciencia, pp. 145-147; DíAZ Y DE OvANDo (1998), tomo I, pp. 100, 101, 110-112, 116.

39 Trífonov, D. N. y Trífonov, V. B. (1984), Cómo fueron descubiertos los Elementos Químicos, Moscú, Editorial Mier, pp. 122-124; RUBINOVICH (1992), pp. 25-29. 
Para entonces el prestigio de Andrés Manuel del Río era más que reconocido en el mundo de la mineralogía. A los treinta y cinco años de edad, en plena capacidad productiva, Del Río se dedicaría a aplicar sus vastos conocimientos a la realidad americana y a difundir sus pesquisas en libros, artículos y notas periodísticas. El descubrimiento más sonado, que al mismo tiempo inauguraba el siglo XIX como una premonición del desarrollo vertiginoso que alcanzarían los saberes científicos en el mundo entero, fue obra del mineralogista madrileño. Entre 1800 y 1801 Andrés del Río analizó en el laboratorio del Real Seminario de Minería de México, un mineral proveniente de la mina de la «Purísima del Cardonal» en el actual Estado de Hidalgo, al que bautizó como «zimapanio» o «plomo pardo de Zimapán». Del zimapanio extrajo una sustancia a la que llamó «pancromo», por la variedad de colores que presentaban sus compuestos químicos, y que después renombró como «eritronio» por el color rojo que adquirían sus sales al exponerlas al fuego ${ }^{40}$. Esto fue justamente lo que Del Río mostró a Humboldt.

A menos de cuatro años de la publicación de la tercera edición de las Tablas Mineralógicas de Karsten de 1800, Andrés del Río las tradujo en 1804 para uso del Seminario de Minería ${ }^{41}$. Mencionó que en los nueve años transcurridos desde la aparición de la primera parte de su Orictognosia, la mineralogía había hecho más progresos que en muchos siglos de otros tiempos. Con esta obra se establecen las bases de una «mineralogía geográfica», al describirse numerosos minerales por localidades. El actual trabajo que se basa en la geognostica fundamental de Lethaea de Heinrich Bronn (1835-38), intentó establecer una secuencia cronológica del organismo fósil, y resumió todo lo que entonces era sabido en stratigraphy y paleontología. Del Río adaptó su sistema stratigraphic y el modelo de secuencias fósiles a la geología de México. Aquí publicó el autor el hallazgo del polémico «eritronio», elemento químico que abrió un debate internacional que iría más allá del año de 1831 cuando Nils Gabriel Sefström ${ }^{42}$ anunciara, como resultado del análisis de un mineral traído de la región de Svalbard, el descubrimiento de un nuevo elemento químico, al cual

40 Del Río. A. (1811), «Sobre el primer descubridor del cromo en el plomo pardo de Zimapán», Diario de México, 11 de Septiembre, pp. 294-295.

41 Del Río, A. M. (1804), Tablas mineralógicas dispuestas según los descubrimientos más recientes e ilustradas con notas por D. L. G. Karsten Consejero del Rey de Prusia, Profesor de Mineralogía, e Inspector del Real Gabinete, Socio y Corresponsal de muchas Academias, Tercera Edición Alemana de 1800 traducida al castellano para el uso del Real Seminario de Minería por..., México, Impresas en México por Don Mariano Joseph de Zúñiga y Ontiveros, 1804.

42 Químico sueco, nació el 2 de junio de 1787, y muere el 30 de noviembre de 1845 . Fue un estudiante de Berzelius, y al estudiar la fragilidad del acero en 1830 descubrió un nuevo elemento químico que registró como vanadio. 
llamó «vanadio» en honor a Vanadis, sobrenombre de Freya, diosa escandinava de la belleza. Según Arnaiz y Freg43, fue Friedrich Woehler quien demostró, ante la Academia de Ciencias Sueca en el año de 1831, que el vanadio no era otro que el eritronio, descubierto por Andrés del Río treinta años antes de los estudios de Sefstroem; y según Rubinovich Kogan ${ }^{44}$, fue Jakob Berzelius quien concluyó, también en 1831, que el vanadio y el eritronio eran uno solo ${ }^{45}$.

En esta misma época, como todo un científico profesional, Andrés del Río se entregó en cuerpo y alma a fortalecer la infraestructura del gabinete de mineralogía y a enriquecer las colecciones mineralógicas con nuevas adquisiciones; unas, fruto del trabajo práctico que los alumnos realizaban, después de concluir los estudios generales, en algún mineral del virreinato; otras, por adquisición a coleccionistas y particulares. De las que se compraron por indicación expresa de Andrés del Río, y que llamaron la atención de propios y extraños por su riqueza y variedad, podemos destacar la colección adquirida al fiscal Juan Eugenio Santelices Pablo; la colección metódica formada por del mineralogista alemán Federico Sonneschmidt, y la colección mineralógica formada por el arquitecto Luís Martín ${ }^{46}$. Con ellas, y las muchas piezas que se acumularon con el tiempo, Del Río enseñó a sus alumnos los caracteres externos de las rocas y minerales, siguiendo las teorías de su profesor Werner, y elaboraría una mineralogía geográfica sin precedente para la Nueva España.

Con una concepción moderna de los procesos de enseñanza-aprendizaje, los estudiantes compartieron con Del Río los ensayos que éste realizaba en el gabinete, sometiendo a riguroso escrutinio los nuevos elementos recolectados en distintos puntos del territorio novohispano. Por otra parte, los estudiantes estaban comprometidos a presentar sus conocimientos y experiencias adquiridos, después de haber concluido sus estudios generales y realizado su ejercicio profesional en algún centro minero, en un acto público. Se trataba del examen público final que los acreditaría como peritos facultativos de minas, acto que por supuesto estaba presidido por sus profesores y las autoridades del Real Seminario de Minería. En los exámenes los estudiantes debían mos-

43 Sandoval Vallarta, M. Y Arnaiz Y Freg, A. (1966), «El Nombre Del Elemento 23», Prieto, Vallarta, Bargalló, Arnaiz y Freg, pp. 73-76.

44 Rubinovich (1992), pp. 25-29.

45 La prolífera labor de Andrés M. del Río, que introdujo las ideas de la escuela neptunista de Werner en Nueva España, se prolongó hasta mediados del siglo XIX, y sentó las bases de la investigación mineralógica futura en México. Prieto, Sandoval Vallarta, BargaLLÓ, y ARNÁIZ Y FREG (1966), pp. 11-79; RUBINOVICH (1992), pp. 3-70; AMORÓS PORTOLÉS (1985), pp. 13-62; CASTILlO MARTOS (2005), pp. 197-241.

46 RAMÍrez (1890), pp. 146-148, 182-183. 
trar los conocimientos adquiridos en orictognosia y geognosia, y las habilidades desarrolladas en el arte de las minas, y exponer sus propias indagaciones tanto en las lecciones de sus profesores como en los trabajos de prácticas, como fundamentales final de su adiestramiento ${ }^{47}$.

\title{
ALUMNOS DE ANDRÉS DEL RÍO, 1795-1805
}

\author{
AÑO ALUMNOS \\ 1795 José Joaquín de Zárate, José Antilla, Manuel Cueto, Félix Rodríguez y \\ Manuel Ruiz de Tejada \\ 1796 Casimiro Chavell, Vicente Herrera y Manuel Cotero \\ 1797 Vicente Valencia, Francisco Álvarez, José Joaquín Zavala y Vicente del \\ Moral \\ 1798 Vicente Castañeda y Isidro Romero \\ 1799 Silvestre Osores y José María Vela \\ 1800 Miguel Álvarez y José Mariano Jiménez \\ 1803 Juan José de Lejarza \\ 1804 Rafael Dávalos y Juan José Rodríguez \\ 1805 José Oteiza, Sixtos Cardona, Rafael Cardoso y Juan Arezorena
}

FUENTE: RAMÍREZ (1890), pp. 135-195. El año de 1801 no hubo alumnos inscritos con Del Río, a decir de Santiago Ramírez. De 1802 carezco de la información correspondiente.

En el Real Seminario de Minería también fue práctica común que los profesores expusieran al término de cada ciclo escolar los temas de sus materias, las novedades habidas en la literatura y los frutos de sus propias investigaciones. Andrés del Río inauguró esa práctica científica y pedagógica. Con un claro espíritu de responsabilidad y un marcado rigor profesional, aprovechó la tribuna para disertar sobre sus investigaciones y mostrar los adelantos de la Orictognosia, la geognosia y el arte de las minas. En su primera comparecencia, el 16 de diciembre de 1795, Del Río expuso las Relaciones entre la composición de un mineral y el depósito que lo contiene ${ }^{48}$. El 27 de octubre de 1797 disertó Sobre los volcanes, impugnando la teoría entonces dominante relativa al origen

\footnotetext{
47 Véase al respecto los bien documentados trabajos de IZQUIERDO (1958), y FLORES Clair (2000).

48 Del Río, A. (1796), «Relaciones entre la composición de un mineral y el depósito que lo contiene», Gaceta de México, Suplemento.
} 
volcánico de algunas rocas ${ }^{49}$. En 1800 presentó su Discurso de las vetas ${ }^{50}$. Y el año de 1803 , en presencia de su invitado especial y condiscípulo en las minas de Freigber, el barón Alejandro de Humbolt, quien presidió el acto público de fin de curso y examinó a los estudiantes de Del Río, este disertó sobre Las formaciones de las montañas en algunos reales de minas, «alejándose de las ideas neptunistas que defendía Humboldt en Pasigrafia geognóstica» ${ }^{51}$.

Como ya se dijo, Andrés Manuel del Río impartió su cátedra de mineralogía de 1795 hasta 1805, en la primitiva casa del Seminario (El Hospicio de San Nicolás). A partir de esta última fecha fue convocado por las autoridades virreinales para examinar los yacimientos minerales de Zacatecas y Guanajuato, las vetas de cinabrio existente en Rincón de Centeno, y los depósitos de hierro de la Intendencia de Michoacán. En los años de 1806 a 1809, y de 1810 a 1811, del Río dejó de impartir sus cursos y realizar los viajes de prácticas con sus estudiantes para cumplir con sus nuevas obligaciones. Lo hizo con pesar, ya que una de las cosas que más le fascinaban era el contacto con los jóvenes. Su lugar lo ocupó el Sr. Juan Arezorena, su alumno de la promoción de 1805, mismo que sólo pudo impartir el curso de mineralogía hasta 1809. El movimiento insurgente obligaría a cerrar el Real Seminario de Minería, y a suspender las actividades académicas en 1810 y 1811. Durante algunos años no se dictó la cátedra de mineralogía, los sucesos de la independencia modificaron la situación interna del Real Seminario. Durante ese periodo, hubo frecuentes cambios en los planes de estudio que resintieron la enseñanza y el desarrollo de la mineralogía.

\section{ANDRÉS DEL RÍO Y SU TRABAJO DE PROMOCIÓN E INNOVACIÓN TECNOLÓGICA}

Los servicios profesionales solicitados al mineralogista madrileño tuvieron otros fundamentos que la sola enseñanza de la ciencia mineralógica, quizás más apremiante y práctica desde el punto de vista económico y productivo. Sacar a la

49 Del Río, A. (1799), «Discurso sobre los volcanes, leído en el Real Seminario de Minería de México, el 31 de Octubre de 1799», Gaceta de México, Suplemento, Noviembre 11; (1800), «Discurso sobre los volcanes», Anales de Historia Natura, tomo II, núm. 6, octubre, pp. 335-347.

50 Del Río, A. (1800-1802), «Discurso de las vetas pronunciado por D. Andrés Manuel del Río en los ejercicios del Real Seminario de Minería», Gaceta de México, Suplemento; (1802-1804), Discurso de las vetas, Anales de Historia Natura, tomo V, núm. 13, junio, pp. 25; tomo VII, núm. 19, febrero, p. 30.

51 Castillo Martos (2005), p. 206; Ramírez (1890), pp. 135-184; DíAZ Y DE Ovando (1998), tomo I, p. 73. 
minería novohispana de la postración en que había caído, aplicando los conocimientos de las ciencias modernas a la resolución de los problemas concretos: localización de yacimientos para producción de azogue, sin el cual lo demás era cosa muerta; desagüe de minas, ricas pero inservibles en esas condiciones; beneficio de minerales preciosos con mejores procesos metalúrgicos; y por si fuera poco, exploración de yacimientos de hierro para su explotación con carácter industrial. En esta tesitura, entre los sabios del virreinato sólo existía una persona con los conocimientos, técnicas y habilidades, y esta era Andrés Manuel del Río.

Andrés Manuel del Río compaginó estas actividades en su vida en México, dándose tiempo para cada cosa. Pero fueron los encargos de desaguar las minas de Morán en el distrito minero de Real del Monte y el establecimiento de una ferrería en la sierra de Coalcomán, las que dejaron ver sus dotes y pericia en el diseño, proyección y ejecución de dos obras de ingeniería, una hidráulica y la otra industrial, las primeras de su género en el nuevo continente.

La máquina de columnas de agua y las minas de Morán. Las minas del Real del Monte, junto con las de Guanajuato y Zacatecas, representaban el símbolo de la riqueza del virreinato de la Nueva España. Pero desde mediados del siglo XVIII la actividad minera había entrado en una etapa de deterioro, resultado, en parte, de dos factores de suyo propios: la extracción de los minerales a mayor profundidad y la abundancia de agua, por efecto de los escurrimientos, que inundaban las galerías y hacían imposible el disfrute de sus vetas. En tales circunstancias, tanto la Corona como las autoridades virreinales buscaron a los mejores hombres de ciencia para encontrar soluciones prácticas y duraderas. Se recurrió, por supuesto, a los pensionados del reino que habían sido enviados a Francia, Inglaterra, Sajonia y Hungría a prepararse en las nuevas técnicas de laboreo de minas, en procesos metalúrgicos e innovaciones tecnológicas. Parece ser que fue a Andrés del Río, a quien se le encomendó recabar toda la información posible sobre los experimentos que se estaban realizando en las minas de Shemnitz, en la Baja Hungría, con una máquina, para extraer sus aguas. El resultado de esta encomienda, se encuentra en la Memoria sobre una máquina con la cual se extraen las aguas de las minas de Shenmitz, en la baja Hungría, que del Río remitió a Antonio Valdéz el 25 de julio de $1788^{52}$, y en la que realiza precisas descripciones tanto de las características de las máquinas de esta naturaleza como de sus dimensiones y material con el que debía ser construida, siempre dependiendo de las condiciones y características del lugar, para operar satisfactoriamente. Este encargo fue, quizás, el primer contacto que del Río

52 Archivo General de Indias (AGI), Mapas y Planos: Minas, 48, e Indiferentes, 1795. Del Río, A. (1788), Memoria sobre una máquina con la cual se extraen las aguas de las minas de Shenmitz, en la baja Hungría, remitida a Antonio Valdez el 25 de julio. 
tuvo con la realidad americana y el vínculo intelectual más próximo para aceptar ser comisionado en su calidad de experto a la Nueva España.

Tan pronto llegó Andrés del Río a la ciudad de México en 1795, y después de impartir el primer curso de mineralogía en el nuevo continente, viajó a las minas de Morán a conocer de cerca los problemas que enfrentaban los mineros para desaguar las galerías. Del Río debió hacer varios viajes a Pachuca, pero es posible que sus estancias fuesen más prolongadas entre 1799 y 1800 , que es el periodo en que se construye y establece la máquina de columnas de agua «cuyo cilindro tiene 26 decímetros de altura y 16 de diámetro». Esta máquina, la primera de este género que se haya construido en América, fue considerada muy superior a las que existían en las minas de Hungría ${ }^{53}$. En ella trabajaron Andrés del Río, a quien se deben los cálculos, el diseño, su construcción y colocación; Pedro Chaussé, un técnico artesano francés, y Nicolás Tubuira. La construcción y adaptación de esta máquina húngara a la mina de Morán tardó cuatro años, y estuvo en operaciones entre 1801 y 1803 , con un costo de 40,000 pesos $^{54}$. Alejandro de Humboldt supo de ella en su viaje a Nueva España, y expresó su reconocimiento a la pericia de Del Río ya que la bomba de columnas de agua «era superior a las que se utilizaban en Hungría» ${ }^{55}$.

El hierro y la Ferrería de Guadalupe. Con el desarrollo de las actividades productivas y la consolidación del sistema colonial en las nuevas posiciones ultramarinas, la economía del virreinato de la Nueva España incrementó el consumo y la demanda de una variedad de artículos y productos que sólo se producían en la península o que eran comercializados en sus posesiones atlánticas a través de ella y sólo de ella. Hay que recordar que la Corona no prohibió su explotación en las tierras colonizadas pero mantuvo el monopolio comercial del hierro y del acero. Por esta razón, el grueso del mineral de hierro que se consumía en el mercado interno novohispano era importado de la metrópoli. Estos minerales provenían de la región de Vizcaya, España, y se embarcaban a Nueva España en lingotes, barras y planchas; junto con ellos, venían importantes remesas de clavos, herramientas de todo tipo para la minería y la agricultura.

El desarrollo de la economía colonial, sobre todo en la última mitad del siglo XVIII, demandó grandes cantidades de este mineral que no siempre la

53 BARgalló, M. (1955), La minería y la metalurgia en la América española durante la época colonial, México, Fondo de Cultura Económica, pp. 342-343.

54 Brading, D. (1975), Mineros y comerciantes en el México Borbónico 1763-1810, México, Fondo de Cultura, pp. 228-229; CASTILlo MARTos (2005), p. 220.

55 Humboldt, A. de, (1978), Ensayo Político sobre el Reino de la Nueva España, México, Editorial Porrúa. 
Corona pudo satisfacer. Durante estos años los conflictos bélicos entre España e Inglaterra, obligaron a la Corona a suspender los envíos, provocando un desabastecimiento en el mercado novohispano y la paralización temporal de las actividades productivas que dependían de ese suministro. Cuando esto ocurría, se mandaba trabajar algunos de los minerales conocidos, pero se abandonaban tan pronto se reanudaba el tráfico marítimo. Un documento de la época señala que «no se pueden trabajar (los yacimientos de hierro) en tiempos de paz por lo barato del hierro y acero español y por falta de combustible» ${ }^{56}$. El científico Alemán Alejandro de Humboldt, refiere que pocos años antes de su llegada a México, a consecuencia de una de tantas interrupciones, «había subido el precio del hierro de 4 a 43 el quintal y el acero de 16 a 260 pesos». En esta ocasión, 1794, se habían explotado con éxito las minas de Tecatitlán, cerca de Colima. Pero se dejaron de trabajar cuando arribaron a Veracruz las primeras remesas procedentes de la península ${ }^{57}$. Respecto de los yacimientos de hierro localizados en el suroeste de Michoacán, aunque se tenía conocimiento de ellos, no llegaron a explotarse sino hasta finales del periodo colonial ${ }^{58}$.

En el marco del conflicto bélico de 1804-1805, entre España e Inglaterra, que cortó las comunicaciones y el comercio entre la metrópoli y sus colonias de ultramar, las autoridades novohispanas elaboraron un plan estratégico para sustituir las remesas externas con la producción interna. Para el efecto, encargaron al mineralogista español Andrés Manuel del Río, profesor del Real Seminario de Minería -institución creada en 1792 por criollos y funcionarios españoles para formar técnicos especializados en la explotación minera-, los estudios y el establecimiento de una ferrería en territorio novohispano.

El mineralogista Del Río recibió con agrado la nueva encomienda, y «tras de estudiar minuciosamente la carta geológica del inmenso territorio novohispano, se decidió que el mineral más barato debía de extraerse de las ricas minas de Coalcomán (ubicadas en el suroeste del entonces Obispado de Michoacán), el punto geográfico más cercano a las regiones (y centros mineros)

56 Florescano, E. y Gil, I. (1973), (Compiladores), Descripciones económicas generales de la Nueva España. 1784-1817, México, SEP-INAH. p. 168.

57 Humboldt, A. (1978), Cap. XI; Othon De Mendlzabal, M. (1946), «Minería y metalurgia mexicana», Obras Completas, México, Talleres Gráficos de la Nación, pp. 77-78.

58 Este apartado recoge en buena medida los resultados de investigación de URIBE SALAS, A. y Uribe Salas, J. A. (1990), «El Mineralogista Andrés Manuel del Río y la Ferrería de Coalcomán», Ciencia y Tecnología en Michoacán, Morelia, Universidad Michoacana de San Nicolás de Hidalgo, pp. 47-62. 
y a la capital del reino, aunque no el más rico de los minerales de hierro del país como lo eran los de Nueva Vizcaya (Durango) y Antequera (Oaxaca)» ${ }^{59}$.

En este proyecto tanto las autoridades como los propios mineros, pusieron todo su empeño y esperanzas, ya que del fierro que se obtuviese de Coalcomán se pensaba abastecer la demanda del mercado interno. Tal circunstancia internacional dio pauta a la introducción y aplicación de moderna tecnología antes ignorada para la explotación del fierro. Andrés Manuel del Río no sólo aplicó sus vastos conocimientos de química, física geología y mineralogía, para la realización de este proyecto, sino que junto con un grupo de alumnos del Colegio de Minería, técnicos y mineros prácticos, diseñó y construyó las instalaciones de la primera ferrería en la América española, que abrió para la ciencia y la tecnología hispanoamericana nuevas perspectivas de desarrollo.

En la ferrería de Guadalupe como fue bautizada esta unidad de producción, Andrés Manuel del Río con el auxilio de sus discípulos, José Mariano Oteiza, Rafael Dávila, José M. Herrera y Rafael Cardoso, construyó un horno de reverbero de grandes proporciones y un alto horno, este último de acuerdo con los diseños de los implantados por La Peyrousse en Europa ${ }^{60}$. Las instalaciones de estos «hornos franceses», como del Río los llamaba, incluían «bóvedas de 30 pies de altura, que solo podían afianzarse en las paredes de una fábrica de bastante elevación ${ }^{61}$. De acuerdo a lo anterior, es muy probable que el alto horno concebido por Del Río en la ferrería de Coalcomán, haya sido similar a los de la «Forja de San Mauricio» instalados en Nueva Francia, y que coincidían con aquél en la altura de 30 pies reportada para ambos casos. Esta similitud no es de extrañar dado el origen común del diseño, lo que explica además, la denominación de «Franceses» dada a sus horno por Del Río62.

Andrés Manuel del Río adoptó el esquema de producción de hierro desarrollado en Inglaterra hacia 1760, el cual estuvo originado y motivado por la sustitución del carbón vegetal empleado hasta entonces como combustible del alto horno, por carbón de coque, que tenía el inconveniente de introducir impurezas en el hierro fundido, principalmente fósforo y azufre, que lo hacían frágil y quebradizo. Dicho esquema de producción consistía en la obtención de un hierro de mejor calidad como resultado de la refundición en hornos de

59 SÁnChez Flores, R. (1980), Historia de la tecnología y de la invención en México, México, Fondo Cultural Banamex, p. 252.

60 Idem.

61 RAMÍREZ (1875), pp. 251-253.

62 Habashi, F. (1975), «Chemistry and Metallurgy in New France», Chemistry in Canada, Canada, The Chemical Institute of Canada, pp. 24-27. 
reverbero, del hierro impuro obtenido en el alto horno ${ }^{63}$. De los primeros ensayos efectuados en la ferreria de Coalcomán, durante el año de 1807, es posible sugerir que Del Río utilizó el horno de reverbero para «pudelar» el hierro fundido impuro obtenido en el alto horno. En la Edad Media, y hasta finales del siglo XIX, muchos países europeos empleaban como método siderúrgico la farga catalana. Se obtenía hierro y acero bajo en carbono empleando carbón vegetal y el mineral de hierro. Este sistema estaba ya implantado en el siglo XV, y se conseguían alcanzar hasta unos $1200{ }^{\circ} \mathrm{C}$. Este procedimiento fue sustituido por el empleado en los altos hornos. En un principio se usaba carbón vegetal para la obtención de hierro como fuente de calor y como agente reductor. En el siglo XVIII, en Inglaterra, comenzó a escasear y hacerse más caro el carbón vegetal, y esto hizo que comenzara a utilizarse coque, un combustible fósil, como alternativa. Fue utilizado por primera vez por Abraham Darby, a principios del siglo XVIII, que construyó en Coalbrookdale un alto horno. El alto horno fue evolucionando a lo largo de los años. En 1784 Henry Cort, aplicó nuevas técnicas que mejoraron la producción, mismas que fueron conocidas por Andrés del Río en su paso por Inglaterra. Henry Cort perfeccionó el proceso de pudelaje en 1784 para convertir el arrabio en hierro dulce en un horno de reverbero. En 1790 había en Inglaterra 81 hornos que empleaban coque para la combustión, frente a 25 que utilizaban carbón vegetal.

Por lo tanto, el proceso de «pudelado» del hierro, inventado por el fundidor inglés Henry Cort hacia 178464, Del Río lo aplicó en Coalcomán, y consistía en «remover, apartar, batir y separar sucesivamente en el horno (de reverbero) $\rangle^{65}$, trozos de hierro refinado que a golpes de martillo recibían forma de lupias o zamarras. Este proceso hacía al hierro más dúctil y maleable debido a la fuerte decarburización sufrida por éste, ya que en el horno de reverbero no existía el riesgo de que las impurezas del carbón, y el carbón mismo, se transmitiera al metal, puesto que solo los gases calientes pasaban del hogar a la parte superior del horno, donde el calor era reflejado por la bóveda sobre el metal a refinar ${ }^{66}$.

63 Derry, T. K. y Wllllams, T. I. (1977), Historia de la Tecnología. desde 1750 hasta 1900, México, Siglo Veintiuno Editores, Vol. 2, pp. 692.

64 El Henry Cort, 1740-1800, Inglaterra. Inventor del proceso puddling, también conocido como el horno reverberatorio. Se le reconoce el haber perfeccionado el molino de balanceo con los rodillos acanalados. El «horno de pudelar» extrae una masa del hierro del horno usando una barra de la agitación. La bola extraída del metal entonces es procesada en una ripia por un martillo el escalonar, después de lo cual se rueda.

65 Derry y WlLLLAMS (1977), Vol. I. pp. 692 y 696.

66 El hecho es que la producción de fundidos -en los que se utilizaba con gran éxito el 
Andrés Manuel del Río construyó además un canal de 3,300 varas (2,765 metros) de largo para aprovechar las aguas del río Astala con las cuales se moverían las ruedas hidráulicas necesarias para los molinos de metales y las fraguas, entre otras instalaciones. Estas aguas eran también indispensables para hacer funcionar las trompas que insuflaban aire al interior de los hornos ${ }^{67}$.

Concluida la carpintería, la herrería, el depósito de agua para las máquinas, abiertos los tiros y socavones para la extracción del mineral ${ }^{68}$, en actividad el corte de madera y la quema de cal, lista la galera de metales, en conclusión el mortero, en corriente el canaleo, puesto el yunque y el martinete, y en disposición de funcionar las trompas y los hornos, «con un soplo excelente, un martinete muy bueno, con un barro (refractario) aceptable y con una construcción bien meditada y perfeccionada, se comenzó a fundir el 29 de abril de 1807, siendo los primeros lances dirigidos exclusivamente por el Sr. Del Río y los jóvenes alumnos de minería que lo acompañaban $\rangle^{69}$.

En el transcurso del año de 1807, ya corregidas las imperfecciones notadas en las primeras experiencias, se comenzaron a producir lupias o zamarras de hierro pudelado con un peso medio de 104 Kilogramos obtenidas a partir de cargas de mineral de 368 Kilogramos, en un tiempo aproximado de 6 horas. «La calidad del hierro no dejó que desear; de la primera remesa que (Del Río) hizo a Guanajuato, a donde llegó el 18 de Agosto de 1808, el Sr. Casimiro Chovell ${ }^{70}$, administrador de la Valenciana, tomó cuatro trozos para experimentarlos, y tan pronto como hizo la experiencia, compró toda la cantidad existente; habiendo tenido igual acogida las remesas posteriores» ${ }^{71}$.

nuevo proceso- era de momento mucho menos importante que la conversión del arrabio en hierro dulce, cuya maleabilidad y resistencia a tensión lo convirtieron en el rey de los metales útiles hasta el descubrimiento del acero barato. DERRY y WLLLLAMS (1977), Vol. 2, pp. 690693; GAYLER, J. L. et al. (1965), A Economic History of Britain, 3.a ed., Harrap.

67 SÁNCHEZ FLORES (1980), p. 252. La trompa o trompe, de invención italiana, fue uno de los métodos más usados para el insuflamado de aire sin la actuación de fuerza manual o animal. Estuvo en uso en el sur de los EUA hasta fines del siglo XIX, La trompa utiliza la fuerza compresiva de una columna de agua que cae dentro de un espacio cerrado, empujando al aire hacia el interior de una cámara y de ésta hacia el interior del horno. Véase: DERRY y WILLIAMS (1977), Vol. 1, p. 211; RAMÍREZ (1890), p. 229.

68 El mineral fundido por Del Río en la ferrería de Coalcomán fue el conocido como «hierro pardo», que corresponde al actualmente denominado Limonita, una hematita hidratada de fórmula química $\mathrm{FeOOH}$.

69 Creir, G.H., Holowaty, M.O., y Squarcy, C. M. (1969), Blast, Furnace-Theory and Practice, New York, H. H. Strasburg, Gordon and Breach Science Publishers, pp. 1-40.

70 Casimiro Chovell había sido alumno de Andrés del Río en el Real Seminario de Minería de México.

71 RAMÍREZ (1890), p. 231. 
«El acierto con que fue establecido y guiado el tratamiento metalúrgico, unido a la buena clase de hierro, dieron el resultado que era de esperarse; y el mismo Sr. Del Río, fijándose en las piezas más delicadas, en cuanto a que más necesitan toda la solidez y resistencia que solo puede dar un tratamiento perfecto, las almandanetas de los mazos y las chapas de los morteros, afirma que estas piezas resultaban de mejor clase y de mayor duración que las de Viscaya» ${ }^{72}$.

Normalizada ya la marcha de la negociación, el 12 de abril de 1809, Del Río solicita autorización al Real Tribunal de Minería para retirarse de ella, presentando el estado de cuenta de los gastos erogados a partir del 25 de noviembre de 1805 hasta el 25 de abril de 1809, ascendiendo éstos a 98,509 pesos 2 reales, habiéndose producido en el tiempo que llevaba funcionando la ferrería, 17,434 Kilogramos de fierro, aparte del empleado en la fabricación de máquinas y demás utensilios de fundición ${ }^{73}$.

A la separación de Andrés del Río de la ferrería de Guadalupe, para retomar sus cursos en el Real Seminario de Minería, las operaciones de ésta quedaron bajo la dirección de José Mariano de Oteiza, uno de sus más apreciados alumnos en dicha institución. El propio del Río, consciente del significado promisorio de la ferrería de Guadalupe para los adelantos de las ciencias y las técnicas del nuevo continente, y también con mucho orgullo, manifestó en la ceremonia de clausura del curso siguiente a su salida de Coalcomán, con fecha de 18 de mayo de 1810, sin saber ni imaginar siquiera de los acontecimientos que se avecinaban, que «mientras corren peligro de desaparecer de la España sus antiquísimas ferrerías bajo la irrupción de los vándalos modernos, aquí trabajamos tranquilamente en experimentos metalúrgicos bajo los auspicios generosos del Tribunal de Minería en un rincón de América, la cual es en el día, gracias a la providencia, el asilo y domicilio pacífico de las ciencias naturales, como en otro tiempo los claustros de los monjes lo fueron de las ciencia abstractas y de las humanidades» ${ }^{74}$. Como más tarde lo referiría Santiago Ramírez, hubiera seguido progresando si no la hubieran destruido los

72 Iden.

73 Quiróz, J. M. (1817), «Memoria del Estatuto; idea de la riqueza que daba la masa circulante en la Nueva España sus naturales producciones en anos de tranquilidad y su abatimiento en las presentes conmociones 1817», FLORESCANO y GIL (1973), pp. 252-254; SÁNCHEz DíAz, G. (1979), El Suroeste de Michoacán: Estructura económico-social 1821-1851. Col. Historia Nuestra Núm. 2, Morelia, Universidad Michoacana, p. 79.

74 Río, Andrés Manuel del, «Discurso sobre la ferrería de Coalcomán, leído en los actos de Minería por D. Andrés del Río», Diario de México. Suplemento, tomo XII, núm. 1629, miércoles 18 de marzo de 1810, pp. 
trastornos ocasionados por la revolución de independencia, que acabaron con ella en octubre de $1811^{75}$.

La ferrería de Guadalupe, a la que Lucas Alamán, discípulo de Del Río, consideró «no solo como un ramo de industria, sino como un elemento necesario para todos los demás, pues éste es el que ha de producir las máquinas de que todos hacen lujo» ${ }^{76}$, que surgía impulsada por factores de tipo internacional (conflicto bélico entre España e Inglaterra), sucumbió esta vez a raíz del movimiento revolucionario de independencia. La guerra que empezó en el año de 1810 hizo abandonar esta empresa.

Insurgentes y realistas se disputaron el control de la ferrería para usos bélicos. Los primeros la aprovecharon para fundir cañones, municiones y utensilios de guerra, hasta su total destrucción por las fuerzas realistas «con lo que se perdió el gasto muy considerable que se hizo para plantarla $\rangle^{77}$.

Todavía en vida de Andrés Manuel del Río, se realizó otro intento por reactivar la ferrería de Coalcomán, con pocos resultados. Los yacimientos de hierro no dejaron de atraer la atención de algunos empresarios y aún del gobierno. En 1827 Pedro Gutiérrez de Salcedo, en sociedad con Mariscal de Castilla, conde del Valle de Orizaba, denunciaron los principales criaderos y planearon la rehabilitación de las antiguas minas y la introducción de tecnología. Para Gutiérrez de Salcedo «ningún otro punto del continente septentrional posee como éste cuantos elementos se requieren para su engrandecimiento; y el impulso que está próximo a darse en la explotación y beneficio de sus metales ferruginosos, aumentará la población, dará ocupación a innumerables brazos que vengan por todas partes... $>^{78}$. Y efectivamente, las actividades que se emprendieron para reactivar la ferrería de Guadalupe, atrajeron a grupos de trabajadores de las comarcas vecinas, la población aumentó y el comercio salió de su postración. Entre 1827 y 1830, según las noticias que se tienen, la población del casco llegó a 1,000 vecinos y a 500 las rancherías anexas. La fábrica de acero establecida por Del Río estaba en reconstrucción cuando estalló la revolución de $1830^{79}$, uno de tantos movimientos políticos

\footnotetext{
75 RAMÍREZ (1890), pp. 210-211.

76 Alamán, L. (1945), Documentos Diversos, México, Editorial Jus, tomo II, pp. 58-59.

77 Alamán, L. (1946), Historia de México, Editorial Jus, tomo II, pp. 377-378; SÁnCHEZ DíAZ. (1979), pp. 79-80

78 GutiÉRreZ De SAlcedo, P. (1905), «Coalcomán», Boletín de la Sociedad Michoacana de Geografía y Estadística, tomo I, núm. 2, p. 8.

79 Diario del Imperio, tomo I, num. II, México, 14 de enero de 1865, p. 44; RoMERo, J. G., (1993), Noticias estadísticas del Partido de Coalcomán en 1863, Morelia, Universidad Michoacana de San Nicolás de Hidalgo, pp. 45-48.
} 
que recorrieron la geografía de México durante la primera mitad del siglo XIX, sembrando la desconfianza y la zozobra entre los empresarios y la población. Aquí, como en otros minerales mexicanos, la explotación quedó restringida a labores realizadas sólo por buscones o rescatadores, hasta bien entrado el siglo antepasado.

\section{A MODO DE CONCLUSIÓN}

El mineralogista Andrés Manuel del Río Fernández llegó a la Nueva España el 20 de octubre de 1794, por el afamado puerto de Veracruz, después de casi tres mese de viaje a bordo del navío de guerra «San Pedro de Alcántara». Traía una encomienda que cumplir, para la cual se había preparado en las mejores instituciones de enseñanza del viejo continente: formar funcionarios mineros calificados en las artes de los metales; impulsar la investigación sobre los recursos mineros y minerales; y promover en los reales de minas del virreinato todo tipo de innovaciones tecnológicas, que asegurasen la buena marcha de las explotaciones mineras y las finanzas del reino. A ello dedicaría el resto de su vida.

En su estancia en Nueva España (1794-1823) y permanencia definitiva en México hasta su muerte acaecida el 23 de marzo de 1849, a la edad de 85 años, cumplió con los objetivos para los que había sido contratado. En los tres aspectos se destacó de manera brillante, circunstancia que le valió el reconocimiento social de la que sería su segunda patria.

En su etapa novohispana recorrió el extenso territorio del virreinato y recogió muestras minerales de los actuales estados de Hidalgo, Zacatecas Oaxaca, Guerrero, Guanajuato y Michoacán; integró las primeras colecciones mineralógicas del Real Seminario de Minería con las que enseñó a sus discípulos los secretos de la orictognosia. En el laboratorio del Seminario escruto las nuevas sustancias minerales e hizo aportaciones al conocimiento universal de las ciencias químicas y mineralógicas, como el descubrimiento del elemento número 23 de la tabla periódica. En el ámbito de la explotación minera dictó reglas prácticas a los mineros para el seguimiento de las vetas y el mejor aprovechamiento metalúrgico de sus menas; diseñó, construyó y operó nuevos artefactos para desaguar las minas, como la máquina de columnas de agua que estableció en la mina de Moran. Su pericia como tecnólogo tuvo un punto de inflexión con el establecimiento de la primera ferrería en la América española. Se trató de una innovación más que de una invención tecnológica, pero en ningún momento de una copia o adopción de los modelos de ferrerias eu- 
ropeas, que Del Río llegó a conocer bien en su experiencia inglesa. En su Discurso sobre la ferrería de Coalcomán ${ }^{80}$, emprende un alegato científico sobre los principios, teorías y técnicas para el establecimiento de una unidad industrial de ese tipo consignada en la «obra moderna, elegante y magistral de La Peirouse».

Andrés Manuel del Río escribió alrededor de 45 trabajos científicos, entre libros, artículos, folletos y notas, y publicó en cuatro idiomas: español, francés, alemán e inglés. Su intensa labor científica y docente la realizaría a la sombra del Real Seminario de Minería de la ciudad de México, después transformado en Colegio de Minería, a cuya institución daría prestigio y renombre internacional. En sus aulas formó a destacados hombres de ciencia, con los cuales compartiría objetivos y metas que lo llevarían a apoyar primero la autonomía e independencia política de la Nueva España, y después, el fortalecimiento de las instituciones científicas de la nueva nación mexicana.

Como profesor titular de la cátedra de mineralogía en el Real Seminario de Minería, después Colegio de Minería, formó en sus aulas a un número importante de hombres de ciencia que contribuirían decisivamente al desarrollo y consolidación de la mineralogía y de la geología mexicana en la segunda mitad del siglo antepasado ${ }^{81}$. Algunos harían carrera política y desempeñarían funciones públicas de gran importancia para el desarrollo del país. Los más se dedicaron al fomento de las ciencias, la docencia y la investigación en los campos de la mineralogía, la geología y la paleontología, contribuyendo decididamente a la institucionalización y profesionalización de las ciencias de la tierra en México ${ }^{82}$.

En cumplimiento de su encomienda, que lo trajo a la edad de 28 años al nuevo continente, Andrés Manuel del Río contribuyó a forjar una cultura científica como parte del imaginario colectivo del nuevo país en construcción. Sus contemporáneos, y discípulos - que en la segunda mitad del siglo XIX tendrían bajo su responsabilidad las riendas de la institucionalización de la ciencia en México - , reconocerían el espíritu, la capacidad y la tenacidad con

80 Río, Andrés Manuel del, «Discurso sobre la ferrería de Coalcomán, leído en los actos de Minería por D. Andrés del Río», Diario de México. Suplemento, tomo XII, núm. 1629, miércoles 18 de marzo de 1810, pp. 2-4.

81 Uribe Salas, J. A. (2005), «Andrés Manuel del Río: su formación científica y sus proyectos de innovación tecnológica», Ponencia al Congreso de Investigación Científica, Universidad Michoacana de San Nicolás de Hidalgo, Morelia, Michoacán, del 12 al 14 de septiembre de 2005.

82 Aguilera, J. G. (1905), «Reseña del desarrollo de la geología en México», Boletín de la Sociedad Geológica Mexicana, Vol.1, México, 1905, pp. 5-117. 
que Del Río había actuado en su vida mexicana para sentar las bases del reconocimiento internacional a las aportaciones científicas que desde esta porción del planeta realizara un pequeño pero sólido grupos de hombres de ciencia.

Fecha de recepción: 20 de mayo de 2005

Fecha de aceptación: 13 de enero de 2006 